\title{
LA MEDIACIÓN COMO INSTANCIA PARA LA REVALORIZACIÓN DEL ROL PATERNO. ESTUDIO EXPLORATORIO-DOCUMENTAL
}

\author{
"MEDIATION AS AN OPPORTUNITY TO REVALORIZE THE PATERNAL ROLE". \\ EXPLORATORY-DOCUMENTAL STUDY
}

\author{
Susana Muñoz Seguel ${ }^{1}$ \\ RomANETte FIgUeroa G UZMÁN ${ }^{2}$ \\ MIRTA O JeDA O VANDO ${ }^{3}$ \\ Abdy Troncoso Córdova ${ }^{4}$
}

Fecha Recepción: 30/09/2011

Fecha Aceptación: 08/11/2011

\begin{abstract}
Resumen
Este estudio exploratorio explicativo, pretende conocer el efecto de la Mediación Familiar, en la revalorización del rol paterno, las relaciones coparentales y el interés superior de los hijos.

Con enfoque cualitativo interpretativo y análisis documental, surge el concepto de coparentalidad, un imaginario social de rol y se construye el rol mediador orientado tanto al sistema familiar, como a la generación de nuevas realidades conceptuales.

Palabras clave: Revalorización, Coparentalidad, Interés superior, Mediador.

Abstract

This exploratory-explanatory study intends to acquaint the reader with the effect of Family Mediation on the revalorization of the paternal role, the coparental relationships and the Superior Interest of the Child.

Using an interpretative qualitative approach and a documental analysis, the concept of coparentality, a social imaginary of the role, and the mediator role arise aimed at the family system as well as at the generation of new conceptual realities.
\end{abstract}

Key words: Revalorization, Coparentality, Superior interest, Mediator.

1 Trabajadora Social, Licenciada en Desarrollo Familiar y Social, Universidad Católica de Temuco. Postítulo en Mediación Familiar y Derecho de Familia UCT. Correo: smunoz@teleton.cl

2 Abogada. Licenciada en Ciencias Jurídicas Universidad Autónoma del Sur de Temuco. Postítulo en Mediación Familiar y Derecho de Familia UCT. Correo: cajvillarrica@gmail.com

3 Psicóloga, Licenciada en psicología. Postítulo en Mediación Familiar y Derecho de Familia UCT. Postítulo "Programa de Especialización en Terapia Familiar Sistémica". Escuela de Psicología. Universidad de La Frontera. Correo: psi.mirta@gmail.com

4 Licenciada en Ciencias Jurídicas y Sociales Abogada, Universidad Autónoma de Chile, Postítulo en Mediación Familiar y Derecho de Familia UCT. Correo: abdytroncoso@hotmail.com

doi: 10.7770/RCHDYCP-V2N2-ART47 


\section{Introducción y formulación del problema}

La Mediación Familiar se torna relevante en procesos de postseparación, al verse afectadas fuertemente las relaciones parentales, que impactan el interés superior de los hijos. Al respecto Cárdenas señala que en este camino de encuentros y desencuentros, surgen cambios y adaptaciones, que derivarán de forma directa en los demás miembros de la familia ${ }^{5}$. En esta crisis la figura del padre puede verse afectada en derechos y obligaciones y afectar a su vez a los hijos, en su desarrollo psicosocial. En este contexto surge la Mediación Familiar como alternativa transformadora, instancia de revalorización, coparentalidad y resguardo del interés superior del niño y surge la pregunta de investigación, ¿cuáles son los efectos que genera la Mediación Familiar en los procesos de revalorización del rol paterno? De este modo las hipótesis orientadoras buscan indagar si la mediación favorece la revalorización y el ejercicio de la coparentalidad, cómo afecta la responsabilización del padre y si propugna además los derechos y el interés superior de los hijos. También busca conocer si los sistemas familiares flexibles y las competencias parentales favorecen la revalorización del rol paterno y cómo actúa el rol del mediador en esta.

Este estudio por lo tanto, pretende contribuir a través del conocimiento de esta temática, al rol que debe ejercer el mediador, en el reconocimiento de la coparentalidad, en contextos de familias no vinculares, reforzando el interés superior del niño y la mayor vinculación del padre en su rol socioafectivo.

\section{La emergencia de la coparentalidad. Encuadre teórico}

La Mediación Familiar se fundamenta según Suares en principios de voluntariedad, neutralidad y confidencialidad. Está sujeta a evolución cultural y se propugna como un mecanismo de resolución de disputas, no adversarial, con un tercero facilitador, orientado a resolver y negociar colaborativamente una solución con aquellos que se encuentran "empantanados" en una disputa, considerando que son capaces de resolver por sí mismos sus conflictos eficientemente ${ }^{6}$. Según Cárdenas, "mediar es ayudar a la gente a confiar en sí misma y en el otro". Esto adquiere relevancia en el ámbito de las relaciones familiares ya que los padres deben considerar que tienen una vida en común por causa de los hijos, debiendo separar el rol conyugal del parental, ya que la crianza exitosa estará influenciada por los acuerdos parentales ${ }^{7}$.

5 Cárdenas, Eduardo José, La mediación en conflictos familiares, Editorial Lumen/Humanitas, Argentina, 2º Edición, 1999.

6 Suares, Marinés, Mediando en Sistemas Familiares, Editorial Paidós, Argentina, 2002.

7 Cárdenas, Eduardo José, obr. cit. p. 16. 
Cárdenas ve en estos últimos decenios una tendencia a equiparar los géneros, un mayor rechazo a las pautas autoritarias, nuevas configuraciones familiares y una disminución a mantener vínculos matrimoniales, todo lo cual ha influido en la forma de relacionarse y enfrentar los conflictos a nivel familiar.

\section{Crisis familiares y divorcio}

Sparvieri señala que la familia constituye un grupo social con microsistemas que interactúan constantemente ${ }^{8}$. Esta interacción estará determinando el funcionamiento del todo y de cada parte en interdependencia, circularidad y equilibrio. Al existir crisis se generarán nuevas organizaciones adaptativas y cíclicas ${ }^{9}$.

Sparvieri ${ }^{10}$ destaca que la familia se desarrolla de forma progresiva, en equilibrio y adaptación, con tareas y aptitudes pertinentes y periodos de desequilibrio que dan origen a nuevas tareas y aptitudes, por lo cual la continuidad de la vida familiar que representa seguridad, cobra relevancia aunque el sistema promueva el desarrollo y la adaptación psicosocial de sus miembros.

Cuando existe crisis y esta es crónica, según Cárdenas ${ }^{11}$ las antiguas formas de resolverla se desechan, disminuye el contacto y se bloquea la autogestión, la familia deja de cumplir su función y puede sobrevenir la separación. Siguiendo a Sparvieri ${ }^{12}$, la separación siempre representará una amenaza, ya que persiste la necesidad de seguridad y pertenencia. Cuando la vida en común termina, se genera angustia, pérdida de seguridad y mayor vulnerabilidad. En este escenario, el control se mantendrá a través del dinero y los hijos, este último de dominio casi exclusivo de la mujer, a través del cual se somete y se presiona.

Sparvieri ${ }^{13}$ refiere que en este proceso postseparación el desafío de los padres se centra en aceptar la responsabilidad de la crianza de los hijos, aunque termine el proyecto de vida y el rol conyugal, ya que el rol parental continúa, en la certeza que una separación adecuada reduce el impacto sobre los hijos, cuando se prioriza en interés de los mismos.

8 Sparvieri, Elena, El Divorcio: conflicto y comunicación en el marco de la Mediación, Editorial Biblos, Argentina, 1997.

9 De La Harpe, Christian, Mediación Familiar, Apuntes de Clases Postítulo Mediación y Derecho de Familia, Universidad Católica de Temuco, Temuco, Chile, 2007.

10 Sparvieri, Elena, obr. cit.

11 Cárdenas, Eduardo José, obr. cit.

12 Sparvieri, Elena, obr. cit.

13 Sparvieri, Elena, obr. cit. 
La ley establece derechos y deberes igualitarios en participación, en relación a los hijos, ya que lo que respecta a los derechos de los hijos estos son recíprocos. Los padres deben educar, mantener relación directa y regular, corregir y entregar alimentos de forma proporcional, es decir ambos deben manutención a los hijos, aunque socialmente se cree que es solo una obligación del padre ${ }^{14}$.

Sparvieri señala que generalmente es la madre quien obtiene la custodia de los hijos, perdiéndose el contacto diario con el padre, modelo de rol masculino y figura de identificación sexual. En Chile la ley tiende a desfavorecer al padre, el Código Civil en su artículo 225 inciso $1^{\circ}$, establece que "si los padres viven separados, a la madre toca el cuidado personal de los hijos", lo cual produce un menoscabo en el rol paterno y un daño en los hijos, vulnerando la Supremacía del Interés Superior del Niño, concepto consagrado en la legislación, que señala que "La preocupación fundamental de los padres es el interés superior del hijo, para lo cual procuran su mayor realización espiritual y material posible y lo guiarán en el ejercicio de los derechos esenciales que emanan de la naturaleza humana, de modo conforme a la evolución de sus facultades" ${ }^{15}$.

La Convención de los Derechos del Niño consagra la protección de este interés superior, reafirmando la participación igualitaria, que asegura "al niño la protección y el cuidado que sean necesarios para su bienestar, teniendo en cuenta los derechos y deberes de sus padres, tutores $u$ otras personas responsables de él ante la ley"16 y plantea que "el niño cuyos padres residan en Estados diferentes tendrán derecho a mantener periódicamente, salvo circunstancias excepcionales, relaciones personales y contactos directos con ambos padres"17.

\section{Paternidad contemporánea y coparentalidad}

El rol paterno contemporáneo se encuentra en transición, entre el padre autoritario y el padre débil y ausente. Desde una dimensión sociológica de la paternidad, "un padre sin compromiso y emocionalmente distante de sus hijos es una figura so-

14 Steffen, María Gisella, Coparentalidad post-separación conyugal. Un paradigma de Tuición Compartida /en/ El Rincón de la Familia, Corporación de Padres por la Igualdad Parental, [on line], №1 2003, [última consulta 5 octubre de 2007] 1-325. Disponible en la World Wide Web: http://orientacionfamiliar. cl.tripod.com/tesis.pdf

15 Sparvieri, Elena, obr. cit. p. 9.

16 Oficina del Alto Comisionado de las Naciones Unidas para los Derechos Humanos, Convención sobre los Derechos del Niño, [on line], [fecha última consulta: 10 de octubre de 2007], Disponible en la World Wide Web: http://www2.ohcr.org/spanish/law/crc.htm

17 Idem. 
cialmente construida pero no biológicamente determinada, por lo que la figura del padre comprometido es una realidad que puede construirse socialmente ${ }^{\prime 18}$.

El inicio de una nueva paternidad se instaló en Europa y América del Norte, a partir de los años sesenta y revolucionó las relaciones familiares. Los cuidados tempranos dejaron de ser exclusivos de las mujeres, sumándose nuevos padres que participaron de la crianza y la custodia monoparental ${ }^{19}$.

Steffen ${ }^{20}$ señala que a partir del cambio social emerge una corriente de pensamiento basada en experiencias de paternidad contemporánea y vivencias de masculinidad, surgiendo un padre potenciado en su rol socioafectivo y vínculo de apego, de relaciones democráticas y cercanas, involucrado en el desarrollo y la construcción de identidad de los hijos, cuyo eje central es la presencia. La paternidad postseparación requiere de capacidades de parentalización y de una normativa legal que involucre a ambos padres de forma activa en el cuidado y las decisiones filiales, lo cual beneficia el desarrollo emocional de los hijos y su inserción social. Al marginar la paternidad activa, producto del costumbrismo legal, se deduce incompetencia y esto provoca la muerte virtual del padre en su rol. La valoración sociocultural de la maternidad, otorga protagonismo femenino, escindiendo la relación coparental, lo que establece diferencias de rol y genera una paternidad de tránsito.

Cárdenas ${ }^{21}$ refiere que un padre cuya figura resulta borrosa para el hijo, retrasa su evolución, confianza en sí mismo y la integración de su identidad y que aunque conviva menos con el hijo, de ningún modo influye menos en su crianza y educación, ni es menos responsable.

De aquí surge la necesidad del ejercicio compartido de roles, la Coparentalidad, que encarna lo que la Convención de los Derechos del Niño establece, "los estados partes respetarán el derecho del niño que esté separado de uno o ambos padres a mantener relaciones personales y contacto directo con ambos de modo regular, salvo si ello es contrario al Interés Superior del Niño"22.

Para Steffen ${ }^{23}$ los hijos requieren de un marco seguro para su desarrollo emocional, el limitar la presencia del padre infringe la dignidad de este y de los hijos, afectando el Interés Superior del Niño, al causar verdaderas padrectomías, lo cual pone a los hijos en posición de objeto fianza, instrumentalizándolos como vía para acceder

18 Steffen, María Gisella, obr. cit. p. 48.

19 Steffen, María Gisella, obr. cit.

20 Idem.

21 Cárdenas, Eduardo José, obr. cit.

22 Oficina del Alto Comisionado de las Naciones Unidas para los Derechos Humanos, obr. cit. p. 4

23 Steffen, María Gisella, obr. cit. 
al dinero, alienándolos y desvinculándolos. Se denigra y subvalora la figura paterna, lo que genera ansiedad por separación en los hijos, que en términos de la Oficina del Alto Comisionado de las Naciones Unidas atenta directamente contra el derecho "que se reconozca que ambos padres tienen obligaciones comunes, teniendo responsabilidad primordial en la crianza y el desarrollo del niño, en función de su interés superior" ${ }^{\prime 24}$.

Steffen ${ }^{25}$ indica que la coparentalidad beneficia las interacciones familiares, si la ley equilibra los derechos, establece igualdad de custodia y coordina la relación coparental, se establecería un ejercicio permanente del rol paterno y un modelo coparental de alianza, que propugna distanciar resentimientos, aminorar la hostilidad y separar conyugalidad de parentalidad, para potenciar un sistema coparental.

\section{Mediación y coparentalidad}

La Mediación fomenta el mantenimiento de la relación entre ex cónyuges, cuya tarea es lograr el bienestar de los hijos y compartir la tarea coparental ${ }^{26}$. La Oficina del Alto Comisionado de las Naciones Unidas señala que esto propende el respeto de derechos, deberes y responsabilidades de los padres para entregar en relación con sus facultades, orientación para que el niño ejerza sus derechos.

Según Cárdenas ${ }^{27}$ la mediación debe favorecer el establecimiento de acuerdos estructurados y duraderos, ayudándole a las partes a cambiar, de modo que recuperen la capacidad para gestionar su vida familiar, relacionando su bienestar personal futuro, con el de los demás miembros.

Cárdenas ${ }^{28}$ señala que el mediador deberá conocer sobre crisis familiares y como movilizar el contexto social, para liberar del estancamiento. Deberá entender los caminos emocionales de la separación, reorientando el potencial humano y priorizando los intereses de los hijos, para generar un cambio cultural.

En concomitancia a lo anterior, De La Harpe refiere la necesidad de potenciar las competencias parentales en cuanto habilidades y aptitudes que se ponen en juego en el cuidado y crianza de los hijos, que aportan seguridad, consistencia y sensibili-

\footnotetext{
24 Oficina del Alto Comisionado de las Naciones Unidas para los Derechos Humanos, obr. cit. p 6

25 Steffen, María Gisella, obr. cit.

26 Steffen, María Gisella, obr. cit.

27 Cárdenas, Eduardo Jose, obr. cit.

28 Idem.
} 
dad respecto de las necesidades de los hijos, por sobre las personales y que resultan vitales para garantizar un adecuado desarrollo psicológico ${ }^{29}$.

Según Baruch y Folger el mediador deberá redefinir la coparentalidad en pro de las necesidades de los hijos y las tareas a cumplir con ellos, en una mediación que sea una instancia transformadora, que busque impedir la inequidad, aliviar el sufrimiento y propender a la independencia de los individuos ${ }^{30}$.

En palabras de Steffen ${ }^{31}$ esto es especialmente importante respecto de la figura del padre, ya que conlleva además de un reajuste en el desempeño de su rol, la no convivencia con el hijo y una relación mediada por la madre, a menudo no empática.

Cárdenas $^{32}$ es esquemático al señalar que la separación es definida tradicionalmente como un hogar donde queda la madre con los hijos y un padre sin lugar válido reconocido por la ley y la cultura. La madre al asumir la crianza se expone a la sobrecarga emocional, social y económica, resultando madres centrales, padres periféricos e hijos sin figuras protectoras. Es en este ámbito que el rol del mediador es relevante en cuanto agente social, al avanzar a un nuevo paradigma familiar: la familia binuclear, donde existe una casa donde vive la madre con los hijos y otra donde vive el padre con los mismos hijos, y entre las cuales existe un camino que los hijos recorren con total libertad. Este objetivo en mediación se traduce en una tarea contracultura de cambio, que busca destrabar y revalorizar al padre en su rol, entendido esto como el resultado de un proceso interaccional de doble vínculo, mediante el cual el rol parento-filial del padre que se ha mantenido periférico y desvarolizado, es validado e integrado de forma positiva y progresiva, en los procesos de desarrollo de los hijos ${ }^{33}$.

Steffen ${ }^{34}$ señala que al validar el rol del padre, portador de cultura, lo hijos no solo integran sus procesos individuales, sino que complementan sus procesos colectivos de aprendizaje, para edificarse como sujetos sociales, medio significativo para estructurarse psíquicamente.

29 De La Harpe, Christian, obr. cit.

30 Baruch Bush, Robert, Folger, Joseph, La promesa de la mediación, Editorial Gránica, Argentina, 2006.

31 Steffen, María Gisella, obr. cit.

32 Cárdenas, Eduardo José, obr. cit.

33 Concepto construido por el equipo investigador y escasamente desarrollado en la teoría.

34 Steffen, María Gisella, obr. cit. 


\section{Encuadre metodológico}

Esta investigación asume un diseño emergente naturalista ${ }^{35}$, lo que tiende a una mayor flexibilidad. El Enfoque Metodológico Cualitativo Interpretativo ${ }^{36}$ busca comprender y analizar los efectos de la mediación en la revalorización del rol paterno a partir de una opción metodológica documental, guiado por hipótesis, que produce datos descriptivos y comprensiones de forma inductiva y flexible.

El tema es abordado según Taylor y Bogdan ${ }^{37}$ de forma holística y particularista desde una mirada sociológica, psicológica y legalista, sin restar valor a ninguna perspectiva. Este es un estudio de tipo exploratorio interpretativo, ya que el tema ha sido escasamente abordado en lo conceptual, de ahí que la revalorización se infiera desde estudios que abordan la coparentalidad, lo cual hace de la mediación un lugar privilegiado para la visibilización y la revalorización del rol paterno.

La muestra fue dirigida y estuvo constituida por documentos cualitativos, fuentes secundarias documentales ${ }^{38}$. Las técnicas utilizadas fueron de lectura y documentación, la selección de la muestra fue informal, a través de muestreo intencional, flexible y dirigido de tipo cualitativo, considerando criterios de disponibilidad, credibilidad y pertinencia, hasta alcanzar el estado de saturación teórica, favoreciéndose la triangulación de investigadoras ${ }^{39}$.

El análisis cualitativo de contenido según Hernández, Fernández y Baptista ${ }^{40}$, favoreció el análisis de significados, expresiones y profundidad de contenido.

35 Valles, Miguel, Técnicas Cualitativas de Investigación Social, Editorial Síntesis, España, 1997.

36 Idem.

37 Taylor, Steven, Bodgan, Robert, Introducción a los Métodos Cualitativos de Investigación, Editorial Paidós, España, 2a Edición, 1996.

38 Valles, Miguel, obr. cit.

39 Taylor, Steve, Bodgan, Robert, obr. cit.

40 Hernández, Roberto, Fernández, Carlos, Baptista, Pilar, Metodología de la Investigación, Editorial Mc Graw Hill, México, 3ª edición, 2003. 


\section{Resultados}

A partir de la $1^{\text {a }}$ Línea de Análisis (ver figura 1), referida a los factores que intervienen en la revalorización del rol paterno en mediación, se construye la "Integración del Concepto de Coparentalidad", que alude según la Oficina del Alto Comisionado, a la importancia de compartir al hijo y las responsabilidades de su cuidado, el cual actúa como revalorizador del rol paterno. Según Haynes ${ }^{41}$, la parentalidad compartida modificó tanto las expectativas de los padres divorciados, como sus roles familiares; en el caso del padre, asumiendo un rol activo, en el caso de la madre compartiendo la crianza de forma similar al matrimonio.

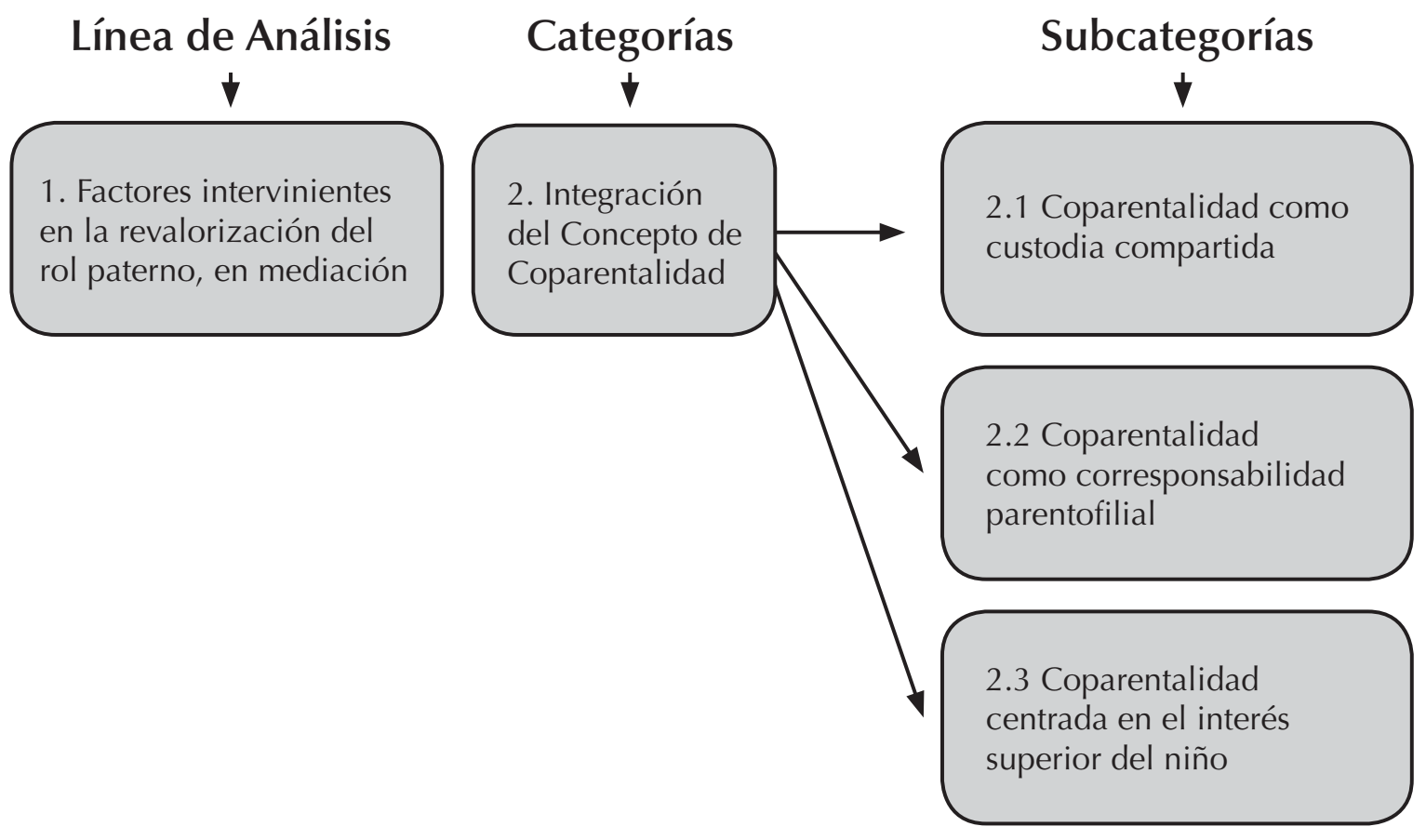

Figura 1

Rodríguez desarrolla un primer concepto: "Coparentalidad como custodia compartida" y señala que debe existir un reconocimiento igualitario de deberes y derechos para ambos padres, en autoridad y responsabilidad respecto de los hijos comunes, debiéndose fomentar la adquisición de modelos solidarios entre ex parejas, ya que siguen siendo socios parentales, lo cual puede tomar diversas formas de custodia: alterna, física conjunta o legal conjunta ${ }^{42}$.

41 Haynes, John, Fundamentos de la Mediación Familiar, Editorial Gaia, España, 2a Edición, 2000.

42 Rodríguez Rey, Tayli Annielys, Custodia Compartida. Una alternativa que apuesta por la no disolución de la familia /en/ Revista Futuros, Editorial CDF, [on line], volumen 3 2005, [20 de noviembre 2007], 1-4. "Disponible en la Word Wide Web: http://www.revistafuturos.info/indices/indice_9_home.htm\#prev". 
En concomitancia, el Parlamento de Canadá señala que la coparentalidad deberá prever la equiparación de derechos en virtud de lo cual "se reconocerá a ambos padres el derecho legal a participar en la crianza y educación de sus hijos" 43 lo que implica sustituir legalmente el concepto de acceso y custodia por el de coparentalidad, promovido en mediación. Esto supone la incorporación del Interés Superior del Niño, principio que motivó la revisión de estas materias y la incorporación de un enfoque de derecho de familia.

De la necesidad de modificar el lenguaje cobra relevancia la Teoría de la Construcción de la Realidad ${ }^{44}$, la cual señala que las creencias acerca del mundo social están construidas por el lenguaje y mediadas por la cultura. De este modo, la construcción de la coparentalidad, favorece la generación de nuevas realidades familiares y el respeto de derechos y obligaciones de ambos padres.

Desde un enfoque teórico conceptual más amplio, surge un segundo concepto, menos legalista y más social: "Coparentalidad como Corresponsabilidad Parentofilial".

Según la Asociación de Padres y Madres Separados de Asturias, la coparentalidad debe propenderse frente a las obligaciones que demandan los hijos y ser un "sistema que respete la voluntad de las partes en la organización de su convivencia y la de sus hijos" 45 . Esto involucra todas las áreas, no solo las estimadas por la ley y debe traducirse en un plan de coparentalidad, donde los padres voluntariamente se constituyan en agentes de sus acciones narrativas, asumiendo responsabilidades y los efectos de sus conductas.

Parkinson concuerda con esto y agrega que la mediación debe fomentar la cooperación y reducir la competencia por los hijos, instándolos a aceptar el rol que cada uno tiene, por lo cual la coparentalidad se entenderá como responsabilidad parental diferenciada ${ }^{46}$.

43 Parlamento de Canadá, Informe del Comité Mixto Especial sobre Custodia y Acceso, [on line], [12 de noviembre 2007. "Disponible en la Word Wide Web: http://www.adiospapa.info/cop/canada.htm", p. 2.

44 Aylwin, Nidia, Del Solar, Olga, Trabajo Social Familiar, Editorial Universidad Católica de Chile, Chile, $2^{a}$ Edición, 2003.

45 Asociación de padres y madres separados de Asturias, Sobre la necesidad de la Mediación en los Procesos de Separación, [on line], [15 de noviembre 2007]. Disponible en la Word Wide Web: http:// imparextremadura.org/documentos/necesidadMediacionFamiliar.pdf, p. 11.

46 Parkinson, Lisa, El Modelo Eco-Sistémico de Mediación Familiar /en/ Revista La Trama Revista Interdiciplinaria de Mediación y Resolución de Conflictos, Editorial Galerna, [on line], № 1 2003, [20 de noviembre 2007], 1-9. "Disponible en la Word Wide Web: http://www.revistalatrama.com.ar/contenidos/ docs/0005_art001.PDF". 
La Asociación de Padres de Familia Separados APFS agrega que esta corresponsabilidad debe ser ejercida independientemente del tipo de custodia que se asignó legalmente, favoreciendo un contacto frecuente y gratificante con los hijos. Esto aumentará los niveles de satisfacción y la calidad del contacto con el padre no custodio, de no ser así puede darse la muerte virtual del padre, marginándolo del ejercicio de su rol, en un contexto de costumbrismo legal ${ }^{47}$.

El Informe Reencuentro ${ }^{48}$ concluye que la coparentalidad establece un nuevo marco de relación, en el cual se redistribuyen derechos y obligaciones que deben tener carácter legal y traducirse en un Plan de Coparentalidad.

Un tercer concepto de coparentalidad se construye, a partir de García: "Coparentalidad centrada en el Interés Superior del Niño", que define la responsabilidad parental como el conjunto de deberes y poderes cuyo fin es asegurar el bienestar material y moral de los hijos, la cual procura la relación estrecha con ambos padres y considera una vulneración de dicho interés, aquellas acciones que liberen de responsabilidad parental a alguno de ellos ${ }^{49}$.

Medina establece que son los padres quienes deberán decidir quien ejercerá la guarda y custodia de los hijos, resguardando el beneficio de sus hijos. El énfasis está en la autodeterminación, pero en función del interés superior del niño ${ }^{50}$.

Rodríguez señala que el mejor interés del niño, será la consideración fundamental en las decisiones sobre cualquier aspecto relacionado con la custodia, lo cual debe derivar en tiempos compartidos con ambos padres, sugiriendo además incorporar presencialmente a los niños en la mediación, a fin de ser oídos, de modo que las decisiones de coparentalidad, se basen en el mejor interés del niño ${ }^{51}$.

Una $2^{\text {a }}$ Categoría de Análisis (ver figura 2), se construye como "Imaginario Social de Género", el cual actúa como regulador de conductas sociales. Las personas

47 Asociación de padres de familia separados APFS, Federación Andaluza de Padres y Madres Separados, Informe Reencuentro sobre la custodia compartida, [on line], [29 noviembre, 2007]. "Disponible en la Word Wide Web: http://www.absurdistan.eu/informe_reencuentro.pdf".

48 Idem.

49 García García, Lucía, Mediación Familiar. Prevención y alternativa al litigio en los conflictos familiares, Editorial Dykinson, España, 2003.

50 Medina Suárez, Isabel, Alés, Javier, La Mediación Familiar como instrumento de protección de la familia al amparo de la nueva ley española del divorcio /en/ TodoMediación.Com, [on line], $\mathrm{N}^{\circ} 2$, 2005, [28 de noviembre 2007], 1-10. "Disponible en la Word Wide Web: http://www.todomediacion. $\mathrm{com} / ? \mathrm{q}=$ node/7".

51 Rodríguez Rey, Tayli Annielys, obr. cit. 
a partir de una valoración colectiva imaginaria establecen parámetros apocales para juzgar y actuar. Estos juicios y actuaciones sociales inciden en el imaginario, el cual actúa como regulador de las conductas ${ }^{52}$.

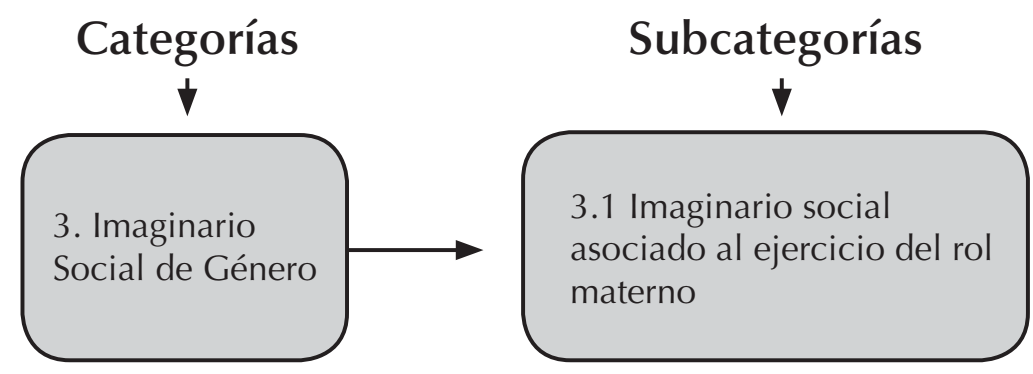

Figura 2

Estos imaginarios sociales median las concepciones de los roles atribuibles a lo femenino y lo masculino y actúan como un obstaculizador para la revalorización del rol paterno. La coparentalidad será más propicia si las ideas estereotipadas sobre el cuidado de los menores se modifican ${ }^{53}$.

Es así como se construye un "Imaginario asociado al ejercicio del rol materno". Bernal señala que existe una idea estereotipada de que la mujer debe encargarse del cuidado de los hijos, lo cual estaría favoreciendo el alejamiento de los padres. Esto genera que se distancien las relaciones, el padre actúe como visita, sin imponer normas por temor a contradecir la autoridad de la madre, sintiéndose cada vez menos influyente en relación a los hijos y manteniendo una relación más cortés que afectiva ${ }^{54}$.

Parkinson agrega que el mediador debe hacer consciente el imaginario familiar y parental subyacente, evitando los sesgos, cuidándose de no asumir que la madre debe ser la única o principal cuidadora de los hijos. Este imaginario en cuanto a práctica y valor se expresa visiblemente desde el marco jurídico, lugar donde el padre no es considerado competente ${ }^{55}$.

52 Díaz, Esther, La Ciencia y el Imaginario Social, Editorial Biblos, Argentina, 1998.

53 Bernal Samper, Trinidad, La Mediación. Una solución a los conflictos de ruptura de pareja, Editorial Colex, España, $2^{a}$ Edición, 2002.

54 Idem.

55 Parkinson, Lisa, El Modelo Eco-Sistémico de Mediación Familiar /en/ Revista La Trama Revista Interdiciplinaria de Mediación y Resolución de Conflictos, Editorial Galerna, [on line], № 1 2003, [20 de noviembre 2007], 1-9. "Disponible en la Word Wide Web: http://www.revistalatrama.com.ar/contenidos/ docs/0005_art001.PDF" 
Ortiz en el contexto español, señala que a pesar de la creciente presión de los padres por obtener la custodia de los hijos, existen dudas de los expertos de que la balanza se vaya a equilibrar, a pesar de estar regulada la custodia compartida, ya que aún prima el criterio biológico e instintivo, de que es la madre por el hecho de parir, la que debe tener y criar a sus hijos, aunque no pueda ocuparse de ellos ${ }^{56}$.

Una $2^{\text {a }}$ Línea de Análisis (ver figura 3 ) hace referencia a los efectos de la revalorización en los sistemas familiares y el interés superior del niño.

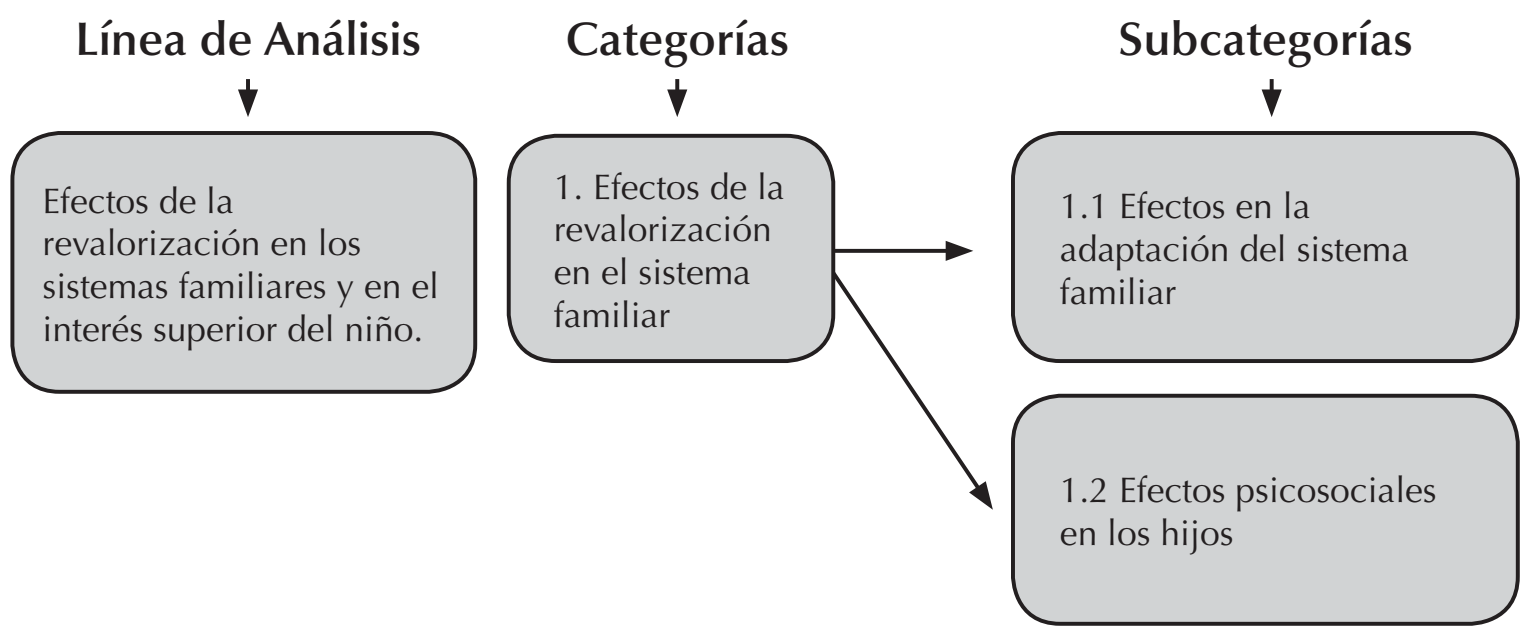

Figura 3

Dentro de los efectos de la revalorización se construyen aquellos que derivan en la Adaptación del Sistema Familiar. Sobre esto Rodríguez ${ }^{57}$ señala que solo mediante la Custodia Compartida se puede satisfacer la necesidad de convivencia con los padres, lo cual es vital en la adaptación al divorcio. La coparentalidad favorece una mayor participación de los padres en la vida escolar de los hijos, genera una mayor disposición para dar alimentos y asistencia médica, entre otros, mejorando las competencias parentales y la cooperación.

La Asociación de Padres y Madres Separados de Asturias ${ }^{58}$, destaca que sistemas que tienden a la coparentalidad tienen efectos en los subsistemas. Disminuye

56 Ortiz, Ana María, Los niños se quedan con papá. El divorcio, la guerra por los hijo /en/ Nuevo Divorcio.Com, Aldan Servicios Jurídicos SL, [on line], No 1 2006, [27 octubre 2007], 1-3. "Disponible en la Word Wide Web: http://www.nuevodivorcio.com/divorciolaguerraporloshijos.pdf"

57 Rodríguez Rey, Tayli Annielys, obr. cit.

58 Asociación de padres y madres separados de Asturias, obr. cit. 
la conflictividad, mejorando la cooperación y la satisfacción relacional con hijos, por lo cual los medios de corrección y castigo son menos necesarios. En relación a los padres, los efectos derivan en una disminución de la presión psicológica y de la culpabilización del otro, mejorando el cumplimiento de los acuerdos pecuniarios. El contacto del padre con los hijos es más frecuente, hay mayor satisfacción en relación a la frecuencia y calidad de la relación y mayor participación en las actividades cotidianas.

Un $2^{\circ}$ efecto se construye en cuanto "Efectos psicosociales en los hijos". Al respecto, el Informe Reencuentro ${ }^{59}$ destaca como efecto principal de la coparentalidad, una mejor adaptación al entorno, la disminución del maltrato físico, un desarrollo adecuado de la autoestima, una mejor relación con los padres y las nuevas parejas, mejor rendimiento escolar y menos problemas psíquicos o asociados a estrés psicosomáticos. Esto es respaldado por una abrumadora cantidad de estudios que establecen que los niños que mantienen contacto regular tras un divorcio, desarrollan mejores niveles de adaptación social y rendimiento escolar.

Rodríguez ${ }^{60}$ coincide en señalar que la coparentalidad se traduce en estabilidad emocional y económica en los hijos. La estabilidad emocional se asocia al establecimiento de relaciones más saludables entre los padres, quienes evitan la culpabilización y aumentan su compromiso en la crianza. La estabilidad económica se asocia a la estabilidad de domicilio, entre otros factores relevantes del bienestar psicológico de los hijos.

Ares de Giordano ${ }^{61}$ proyecta estos efectos e indica que el impacto de la mediación repercutirá en la generación futura, ya que al evitar que el hijo sea el centro de un conflicto que no es suyo, se le permite abordar con más serenidad su propia conyugalidad y su papel de progenitor.

Desde una $3^{\circ}$ Línea de Análisis (ver figura 4), referida al Rol del Mediador en la Revalorización del Rol Paterno, se construye el Rol según Principios Orientadores.

59 Asociación de padres de familia separados APFS, obr. cit.

60 Rodríguez Rey, Tayli Annielys, obr. cit.

61 Ares De Giordano, Consuelo, Mediación, conflictos y soluciones razonables, Editorial Jurídicas Cuyo, Argentina, 2004. 

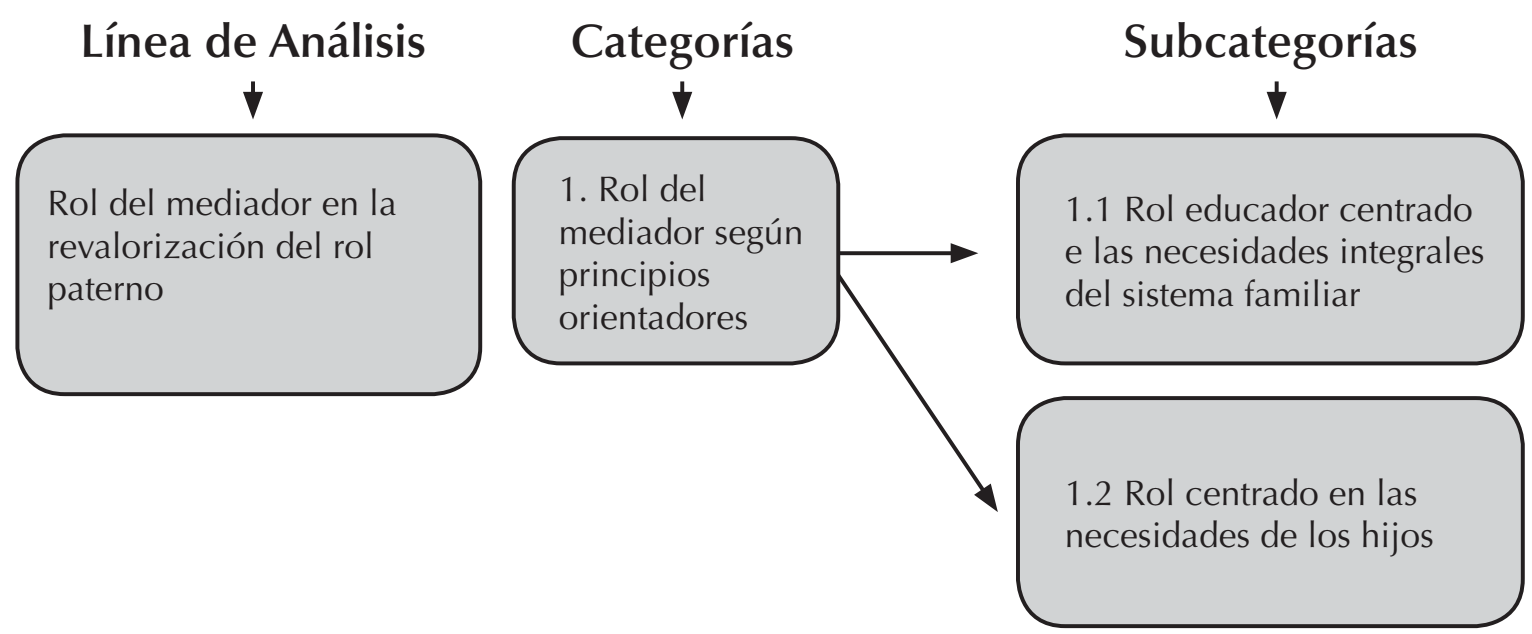

Figura 4

Al respecto Haynes describe el rol del mediador centrado en las necesidades del sistema familiar, en cuanto sociabiliza y promueve el ejercicio de nuevos roles parento-filiales y concentra su interés en las necesidades de los padres y los hijos. Su rol es ser educador de nuevos roles parentales, actuando como mediador y educador, ayudando a mantener el control sobre las propias decisiones ${ }^{62}$.

García señala que el mediador debe establecer las responsabilidades de ambos padres en los temas cotidianos de la crianza, además de trabajar con el progenitor padre, en esclarecer una posición de responsabilidad compartida ${ }^{63}$.

Un segundo Rol Mediador se construye como un Rol Centrado en las Necesidades de los Hijos. Viveros ${ }^{64}$, postula que el fin la mediación es establecer acuerdos que aseguren el sustento material y espiritual de los niños. Esto implica comunicación con el padre no custodio y el aseguramiento de los medios necesarios para un adecuado desarrollo y nivel de vida. Esto supone que tanto la presencia del padre como la del mediador se justifican en mediación, porque existe un denominador común que los une, la satisfacción de las necesidades de los niños y su bienestar; siendo la provisión integral, el principal objeto en mediación. De este modo se busca que los padres generen arreglos especiales, regulen situaciones nuevas y hagan frente a la ruptura y al cese de la convivencia, situaciones en que la coparentalidad se pone en riesgo.

62 Haynes, John, obr. cit.

63 García, Lucía, obr. cit.

64 Viveros Caviedes, Felipe, Mediación Familiar y Derechos del Niño /en/ Revista Centro de Resolución Alternativa de Conflictos, Universidad Católica de Temuco, No 3 2002, Temuco, Chile, 160-167. 
La Asociación de Padres y Madres Separados de Asturias ${ }^{65}$, concuerda en que cada vez es más necesario reeducar a las familias postdivorcio, para disminuir el impacto sobre los hijos, procurando que se sientan protegidos, seguros, queridos, aceptados y por sobre todo se les garantice una posición cómoda, respecto de ambos progenitores.

Bernal ${ }^{66}$ también releva la necesidad de enseñar a los padres a comunicarse, para que juntos proporcionen un futuro seguro a los hijos. De este modo, el mediador dibuja un esquema con los padres, de lo que será su aporte al cuidado y atención de los menores, en lo emocional y material, sentando así las bases de un buen funcionamiento. Centrarse en las necesidades de los hijos implica comprender los caminos emocionales por los cuales viaja la familia, reorientándolos en su potencial humano, generando cambio para abordar la crisis, para resguardar el interés superior de los hijos, en función de lo cual el mediador definirá la coparentalidad y las tareas a cumplir, lo que permitirá satisfacer necesidades frustradas y aliviar el sufrimiento.

Parkinson ${ }^{67}$ señala que el mediador debe considerar que los niños pueden estar sufriendo, de modo de alentar a los padres a asumir el rol que a cada uno les compete, en distintas áreas de responsabilidad parental. El mediador debe redirigir los recursos hacia un trabajo creativo, para mejorar las relaciones parentales y parentofiliales, lo que además implica no asumir que debe ser la madre la sola cuidadora.

Respecto del Interés Superior del Niño y el lugar que ocupa el padre, Rodríguez ${ }^{68}$ señala que la continuidad del vínculo es ante todo un derecho del niño y después un derecho y un deber del padre.

Del análisis documental también surge un segundo Rol del Mediador Orientado a la Praxis (ver figura 5), entendida esta como los elementos diferenciadores que le permiten en la práctica y la reflexión, fomentar la revalorización.

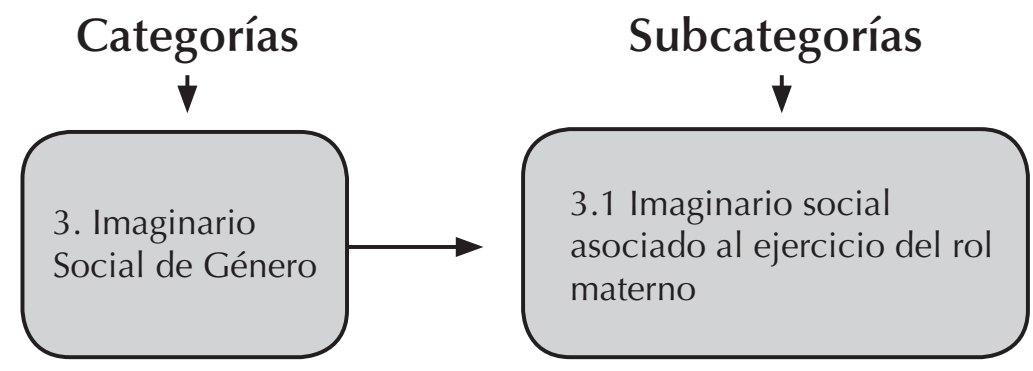

65 Asociación de padres y madres separados de Asturias, obr. cit.

66 Bernal Samper, Trinidad, obr. cit.

67 Parkinson, Lisa, obr. cit.

68 Rodríguez Rey, Tayli Annielys, obr. cit. 
Desde Haynes ${ }^{69}$ se construye un Rol Centrado en la Construcción de Nuevas Realidades, quien desde una postura visionaria, releva la necesidad de enfrentar los prejuicios y cambiar el lenguaje, evitando el uso de términos que supongan el enjuiciamiento de la realidad, tales como matrimonio fracasado, custodia y régimen de visitas; prefiriendo término de la relación, parentalidad, tiempo compartido con los padres y residencia. Esto ya que los términos jurídicos tienen una fuerte connotación ganador-perdedor y se refieren a poseer a los hijos, en vez de apoyar los objetivos de su cuidado futuro. Por lo tanto su rol será modificar el lenguaje de las partes en uno contradictorio, distinto al vocabulario de tribunales.

También será necesario educar a la sociedad para aprender a ser padres y madres separados, familiares de padres separados, amigos e hijos de padres separados ${ }^{70}$. En este sentido, la Custodia Compartida como concepto social validado, se constituye en una nueva filosofía de vida en la que los padres tendrán que aprender a compartir el amor de sus hijos, las responsabilidades y también los gastos.

\section{Conclusiones. Principales hallazgos}

A partir de los hallazgos orientados por el objetivo general, se concluye la existencia de un factor preponderante en la comprensión de la realidad social, que actúa como obstaculizador de la revalorización del rol paterno ${ }^{71}$ y que da cuenta de un Imaginario Social de Género, culturalmente compartido que genera estereotipos culturales asociados a la maternidad y a la paternidad, naturalizándolos. En este contexto el padre queda disminuido en su rol, versus una madre que adquiere un rol protagónico en la crianza de los hijos, lo cual se traduce en un marco legal que la respalda y favorece, reduciendo el rol paterno a la provisión de alimentos y a la relación directa y regular. Lo anterior transgrede la Convención de los Derechos del Niño y vulnera la obligación recíproca que la ley establece a los padres, respecto de los hijos. Este marco legal adverso al padre, de no valorización que le atribuye incompetencia, vulnera derechos de padres e hijos y colabora en la mantención de un imaginario social de género tradicionalista y sesgado.

Otro hallazgo en cuanto facilitador de la revalorización del rol paterno, es la emergencia en contextos de mediación, del Concepto de Coparentalidad, promovido por imaginarios de paternidad más contemporáneos, cuyas características permiten un mayor involucramiento afectivo con los hijos. Es así como la Coparentalidad surge y se desarrolla desde tres miradas, la Custodia Compartida, en la cual se regula legal-

69 Haynes, John, obr. cit.

70 Asociación de padres de familia separados APFS, obr. cit

71 Ver Anexo № 2, Proceso de Revalorización del Rol Paterno en Mediación. 
mente la igualdad de derechos y deberes para ambos padres, La Corresponsabilidad Parento-filial, en cuanto un sistema compartido de obligaciones parentales y la Coparentalidad Centrada en el Interés Superior del Niño, orientada a asegurar el bienestar de los hijos y que guía las responsabilidades y decisiones familiares.

En Chile no existe la figura legal de la Coparentalidad o Custodia Compartida en los términos antes mencionados, que entreguen opciones al ejercicio parental, aunque los padres estén dispuestos a responsabilizarse, por lo que la posibilidad de construirla se limita solo a los contextos de mediación y a los acuerdos creativos que en estos se propicien. La mediación se constituye en la instancia para reeducar a los padres, en beneficio de los hijos y del cambio cultural y judicial, mediante la visibilización del impacto que la coparentalidad tiene sobre el sistema familiar.

Por lo tanto es posible señalar que la Mediación propugna los derechos y el Interés Superior del Niño, ya que este interés es central en mediación. No obstante, los autores hacen la distinción respecto del lugar que ocupa este interés, transitando desde sistema familiar como un todo integrado y el interés de los hijos, lo cual queda expresado en las distinciones de coparentalidad.

Se reafirma así que la Mediación favorece la revalorización del rol paterno y el ejercicio de la coparentalidad, ya que promueve la cooperación, toda vez que apuesta a la equiparación de roles y a una mayor presencia del padre, como figura significativa. La mediación asume la responsabilidad que no asumen los sistemas culturales y de justicia, al demostrar que la coparentalidad es un modelo de corresponsabilidad pertinente y efectivo.

Es posible concluir por lo tanto, que la revalorización del rol paterno tiene efectos positivos en la adaptación del sistema familiar y el desarrollo psicosocial de los hijos. Aumenta la participación de los padres, disminuye la conflictividad y mejora las competencias parentales, los hijos se adaptan mejor al entorno social y tienen una mayor estabilidad emocional. Toda esta capacidad de aprendizaje y adaptación se traduce en deuteroaprendizajes, útiles en otros ámbitos de la vida.

En relación a las características de los sistemas familiares, es posible concluir que aquellos sistemas flexibles tienden a ajustarse y funcionar mejor con un modelo de coparentalidad, puesto que sus planes tienden a ser más creativos, en función de las necesidades de convivencia de los padres.

Otro hallazgo importante de destacar además, es como la revalorización del rol paterno actúa positivamente en la responsabilización del padre ausente, el equilibrio de roles y el desarrollo integral de los hijos. A partir de los efectos de la revalorización, la figura de padre se confirma y se valida, mejorando el contacto y la calidad de la relación. Entre los padres mejora la convivencia, la responsabilización y la equiparación de obligaciones, lo cual repercute positivamente en los hijos. 
Respecto del rol del mediador se concluye que este debe orientarse según principios, a las necesidades del sistema familiar, poniendo énfasis en la autodeterminación y el cambio de la estructura familiar, para favorecer la transformación y la coparentalidad. También debe orientarse a las necesidades de los hijos, promoviendo el Interés Superior del Niño en las decisiones, resguardando la comunicación con el padre y la protección de los hijos.

Como hallazgo es interesante señalar desde la praxis, que el rol del mediador debe propender a la construcción de nuevas realidades. Se plantea la necesidad de establecer nuevos lenguajes, que excluyan las connotaciones legalistas, por lo que será relevante conocer la postura desde la cual interviene el mediador y si su quehacer se centra en las necesidades de los hijos y su interés superior o es más integral, orientándose a las necesidades de la familia como sistema. En Chile no es posible inferir la existencia de uniformidad de criterios en mediación, que permitan concluir la existencia de principios orientadores, habiendo distinciones entre centros de mediación, respecto del valor que tiene este interés y de la relevancia de revalorizar al padre en su rol, como garante del bienestar de sus hijos. 


\section{Bibliografía}

Ares de Giordano, Consuelo, Mediación, conflictos y soluciones razonables, Editorial Jurídicas Cuyo, Argentina, 2004.

Aylwin, Nidia, Del Solar, Olga, Trabajo Social Familiar, Editorial Universidad Católica de Chile, Chile, 2 2a Edición, 2003.

Baruch Bush, Robert, Folger, Joseph, La Promesa de la Mediación, Editorial Gránica, Argentina, 2006.

Bernal Samper, Trinidad, La Mediación. Una solución a los conflictos de ruptura de pareja, Editorial Colex, España, 2ª Edición, 2002.

CÁRDENAS, Eduardo José, La Mediación en conflictos familiares, Editorial Lumen/Humanitas, Argentina, 2a edición, 1999.

Díaz, Esther, La Ciencia y el Imaginario Social, Editorial Biblos, Argentina, 1998.

García García, Lucía, Mediación Familiar. Prevención y alternativa al litigio en los conflictos familiares, Editorial Dykinson, España, 2003.

HAYNES, John, Fundamentos de la Mediación Familiar, Editorial Gaia, España, $2^{\text {a }}$ Edición, 2000.

Hernández Sampieri, Roberto, Fernández, Carlos, Baptista, Pilar, Metodología de la Investigación, Editorial Mc Graw Hill, México, $3^{\text {a }}$ Edición, 2003.

Sparvierı, Elena, El Divorcio: conflicto y comunicación en el marco de la Mediación, Editorial Biblos, Argentina, 1997.

Suares, Marinés, Mediando en Sistemas Familiares, Editorial Paidós, Argentina, 2002.

TAYlor, Steven, Bodgan, Robert, Introducción a los Métodos Cualitativos de Investigación, Editorial Paidós, España, 2a Edición, 1996.

Valles, Miguel, Técnicas Cualitativas de Investigación Social, Editorial Síntesis, España, 1997.

\section{Artículo de Publicaciones periódicas en soporte físico}

Viveros Caviedes, Felipe, Mediación Familiar y Derechos del Niño /en/ Revista Centro de Resolución Alternativa de Conflictos, Universidad Católica de Temuco, $\mathrm{N}^{\circ}$ 3 2002, Temuco, Chile, 160-167. 


\section{Artículo de Publicaciones periódicas en soporte electrónico}

Medina Suárez, Isabel, Alés, Javier, La Mediación Familiar como instrumento de protección de la familia al amparo de la nueva ley española del divorcio /en/ TodoMediación.Com, [on line], No 2, 2005, [28 de noviembre 2007], 1-10. "Disponible en la Word Wide Web: http://www.todomediacion.com/?q=node/7".

Ortiz, Ana María, Los niños se quedan con papá. El divorcio, la guerra por los hijo /en/ Nuevo Divorcio.Com, Aldan Servicios Jurídicos SL, [on line], No 1 2006, [27 octubre 2007], 1-3. "Disponible en la Word Wide Web: http://www.nuevodivorcio. com/divorciolaguerraporloshijos.pdf".

Parkinson, Lisa, El Modelo Eco-Sistémico de Mediación Familiar /en/ Revista La Trama Revista Interdiciplinaria de Mediación y Resolución de Conflictos, Editorial Galerna, [on line], No1 2003, [20 de noviembre 2007], 1-9. "Disponible en la Word Wide Web: http://www.revistalatrama.com.ar/contenidos/docs/0005_art001.PDF".

Rodrícuez Rey, Tayli Annielys, Custodia Compartida. Una alternativa que apuesta por la no disolución de la familia /en/ Revista Futuros, Editorial CDF, [on line], volumen 3 2005, [20 de noviembre 2007], 1-4. "Disponible en la Word Wide Web: http:// www.revistafuturos.info/indices/indice_9_home.htm\#prev".

Steffen Cáceres, María Gisella, Coparentalidad post-separación conyugal. Un Paradigma de Tuición Compartida Chileno /en/ El Rincón de la Familia, Corporación de Padres por la Igualdad Parental, [on line], No 1 2003, [5 de octubre 2007], 1-325. "Disponible en la Word Wide Web: http://orientacionfamiliar.cl.tripod.com/tesis.pdf".

\section{Otros Documentos Electrónicos}

Asociación de padres y madres separados de Asturias, Sobre la necesidad de la Mediación en los Procesos de Separación, [on line], [15 de noviembre 2007]. "Disponible en la Word Wide Web: http://imparextremadura.org/documentos/necesidadMediacionFamiliar.pdf".

Asociación de padres de familia separados APFS, Federación Andaluza de Padres y Madres Separados, Informe Reencuentro sobre la custodia compartida, [on line], [29 noviembre, 2007]. "Disponible en la Word Wide Web: http://www.absurdistan. eu/informe_reencuentro.pdf".

Código Civil, De los derechos y obligaciones entre los padres y los hijos, [on line], [7 de octubre 2007]. "Disponible en la Word Wide Web: http://www.chilein. com/c_civil6.htm 
Oficina del Alto Comisionado de las Naciones Unidas para los Derechos Humanos, Convención sobre los Derechos del Niño, [on line], [10 de octubre 2007]. "Disponible en la Word Wide Web: http://www2.ohchr.org/spanish/law/crc.htm".

Parlamento de Canadá, Informe del Comité Mixto Especial sobre Custodia y Acceso, [on line], [12 de noviembre 2007. "Disponible en la Word Wide Web: http:// www.adiospapa.info/cop/canada.htm".

\section{Otros Documentos (Cátedras de Postgrado)}

De la Harpe, Christian, Mediación Familiar, Temuco, Chile: Universidad Católica de Temuco: Postítulo Mediación y Derecho de Familia. 2007 [Apuntes]. 


\section{Anexos}

Anexo No 1: Resultados

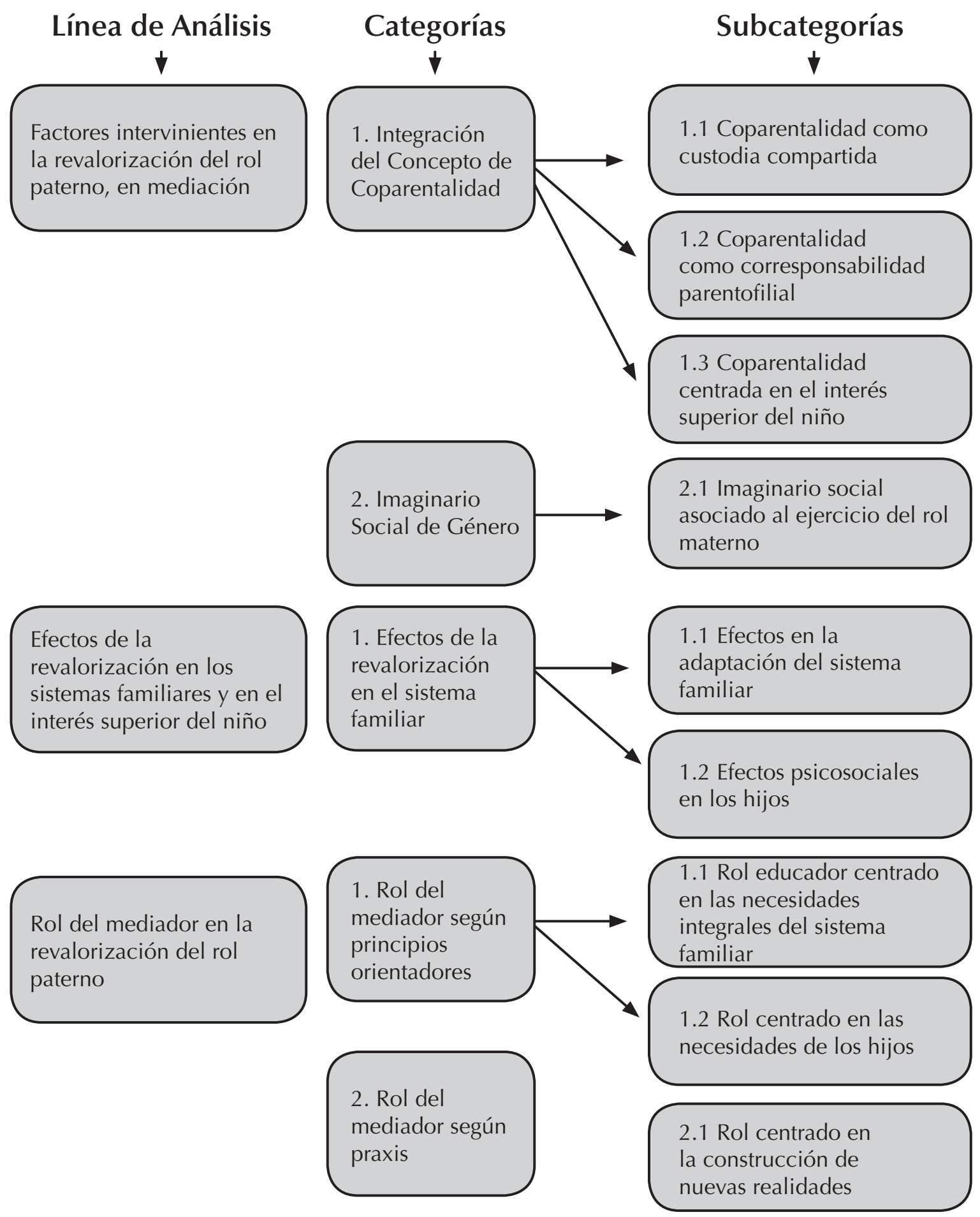


Anexo No 2: Proceso de Revalorización del Rol Paterno en Mediación

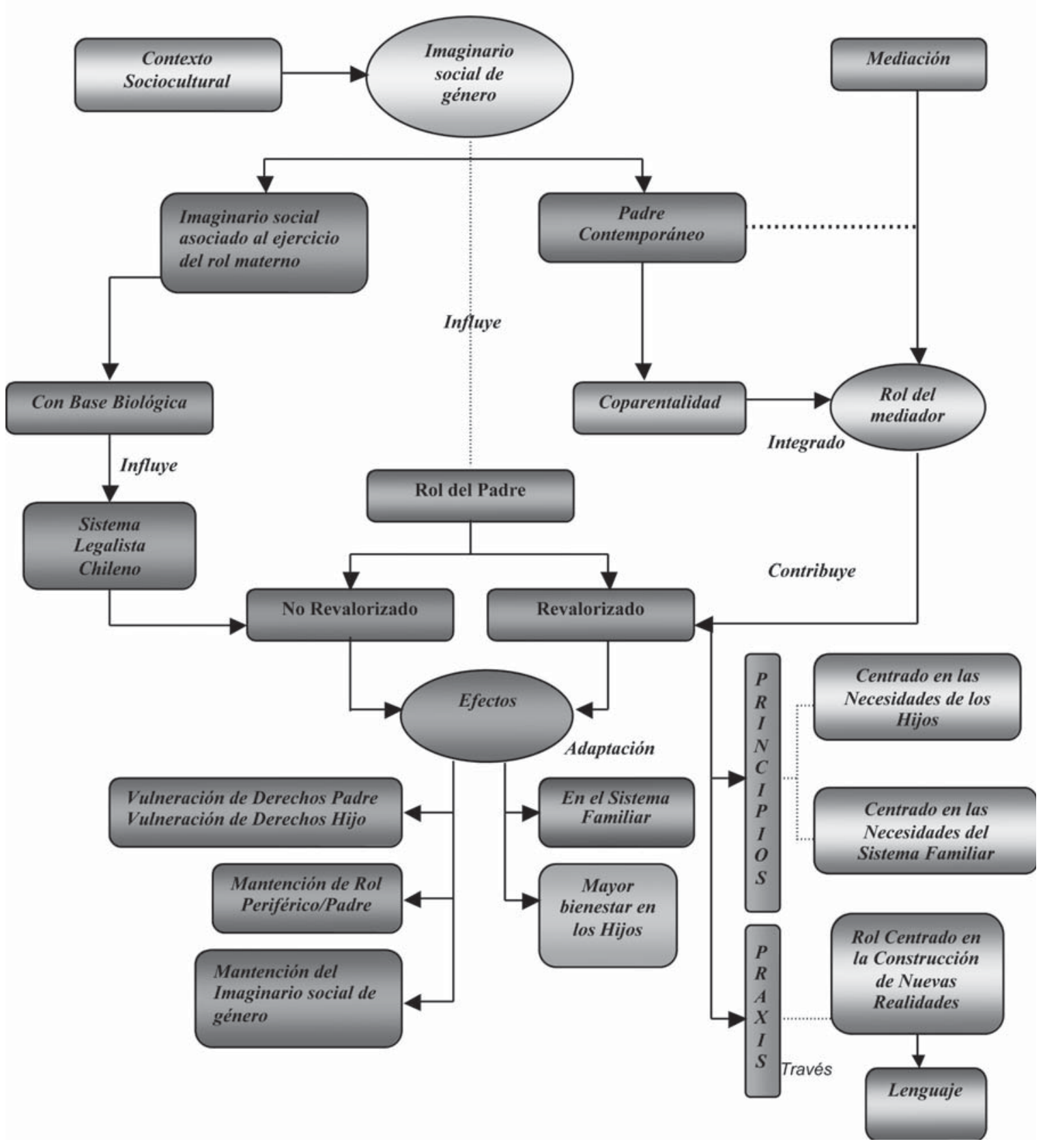

